\title{
Physics webpages create barriers to participation for people with disabilities: five common web accessibility errors and possible solutions
}

\author{
Erin Scanlon ${ }^{1,2}$, Zachary W. Taylor ${ }^{3}$, John Raible ${ }^{4}$, Jacob Bates ${ }^{4}$ and Jacquelyn J. Chini ${ }^{1^{*}}$ (1)
}

\begin{abstract}
Background: While there have been numerous calls to increase the participation of people with disabilities in STEM, many postsecondary institutions are not equipped to support students with disabilities. We examined the accessibility of 139 webpages from 73 postsecondary institutions in the USA that contained information about the undergraduate physics curriculum and graduate research programs. We selected these webpages as they are common entry points for students interested in pursuing a physics degree. We used Tenon and Mac OS X's VoiceOver software to assess the level of accessibility of these webpages as measured by alignment with the Web Content Accessibility Guidelines (WCAG) 2.0.
\end{abstract}

Results: We found that only one webpage had minimal accessibility errors (i.e., 10 errors), while the other webpages had numerous accessibility errors. Five specific error types accounted for the majority of all errors. The five most common errors were related to information, structure, and relationships of content (1.3.1 Level A; 39.7\%); text alternatives for non-text content (1.1.1 Level A; 27.0\%); information about link purpose (2.4.4 Level A; 14.7\%); capability to resize text (1.4.4 Level AA; 10.0\%); and information about the name, role, and value of user interface components (4.1.2 Level A; 11.2\%).

Conclusions: We present and describe the five common accessibility errors we identified in the webpages in our sample, suggest solutions for these errors, and provide implications for students with disabilities, instructors and staff, institutional administration, and the broader physics community.

Keywords: Accessibility, Webpage accessibility, STEM, Physics Education, Americans with Disabilities Act, Section 508 , Disability studies

\section{Introduction}

There have been many calls to increase the number of science, technology, engineering, and mathematics (STEM) qualified professionals, and specifically participation of people with disabilities, in the STEM workforce. For example, in the USA, the National Science Foundation (NSF, 2011) stated, “Tomorrow's STEM workforce must draw on the talents and interests of all

\footnotetext{
*Correspondence: Jacquelyn.Chini@ucf.edu

${ }^{1}$ Department of Physics, University of Central Florida, Orlando, FL, USA

Full list of author information is available at the end of the article
}

sectors of the nation's diverse population. NSF will intensify our efforts to expand participation in the STEM workforce by currently underrepresented segments of the population-women, minorities, and persons with disabilities" (p. 3). However, to enter the STEM workforce, students need to matriculate through STEM degree programs and students with disabilities are underrepresented in postsecondary STEM programs (NCSES, 2015).

Aside from workforce needs, a just society provides opportunities for all individuals to engage their 
interests. ${ }^{1}$ People with disabilities demonstrate high interest in STEM during the transition from high school to college, but their representation in STEM decreases throughout postsecondary education and into the workforce. Government agencies, including the National Science Foundation (NSF; NSF, 2019) and National Center for Education Statistics (NCES; NCES, 2019), collect data related to the representation of people with disabilities in the postsecondary and workforce environments. The surveys used to collect these data ask different questions and use different definitions of disability and disability categories (NSF, 2019). The population statistics listed below include mobility and physical disabilities, emotional and mental health disabilities, vision and hearing disabilities, and health-related disabilities (Scott, 2009). Looking at statistics in the USA, in 2012, students with disabilities made up $11 \%$ of the undergraduate student population (NCSES, 2015) and in 2017 represented $19.8 \%$ (NSF, 2019) as determined using different measures (NCES, 2016). Also, undergraduate students with and without disabilities enroll in science and engineering majors at similar rates (28.0 and $27.6 \%$, respectively; NSF, 2019).

However, in 2017, 7.4\% of doctoral degrees in physical sciences were awarded to people with disabilities (NSF, 2019), and people with disabilities make up 9.3\% of employed physical scientists with disabilities. It makes sense that the number of employed physical scientists has a higher representation of people with disabilities because people can gain disabilities as they age. For example, $8.4 \%$ of employed people with disabilities in STEM were diagnosed at birth, $13.9 \%$ were diagnosed at ages $1-9,15.2 \%$ were diagnosed at ages $10-19,11.4 \%$ were diagnosed at ages $20-29$ (i.e., typical college age), $10.2 \%$ were diagnosed at ages $30-39$, $19.1 \%$ were diagnosed at ages $40-49$, and $21.9 \%$ were diagnosed at ages 50-75 (NSF, 2019). An important feature of the statistics presented here is that they represent people who have been diagnosed with disabilities and not those who have a disability but have not been diagnosed (NSF, 2019).

There are a myriad of factors that may contribute to people with disabilities ceasing participation in STEM, including different academic preparation than their peers (whether caused by restrictive Individual Education Plans or their own interests; Sparks \& Lovett, 2009), lack of curricular materials designed to support students with disabilities (Scanlon et al., 2018a, b), lower sense of belonging in the postsecondary community (Kurth \&

\footnotetext{
${ }^{1} \mathrm{We}$ are committed to fostering and supporting disability justice (Berne et al., 2018) in our work and thus prioritize equitable access to STEM education and the STEM workforce, which also means equitable opportunity to choose not to participate in the STEM workforce.
}

Mellard, 2006), lack of faculty preparation to support students with disabilities (Love et al., 2014; Moriarty, 2007; Scott, 2009; Thompson et al., 1997), and motivational factors such as lower expectations of success in science and mathematics (Bittinger, 2018).

Another contributing factor to the decrease in participation by people with disabilities is related to the accessibility of the information related to academic programs. Kane et al. (2007) state: "University [web]sites that are not accessible may exclude people with disabilities from participation in educational, social and professional activities" (p. 148). In 2011, 93\% of institutions of higher education had a main website where information about the institution was housed and Raue and Lewis (2011) reported that only $24 \%$ of these institutions follow established accessibility guidelines (Raue \& Lewis, 2011). This means that at least some of the information presented on these institutions' websites are not accessible to everyone; this inaccessible information can be a significant barrier to participation for people with disabilities. If prospective students do not have access to the information about an institution, they may be less likely to enroll at that institution (Burdett, 2013; Daun-Barnett \& Das, 2013). The inaccessibility of postsecondary institutions' websites creates a barrier to participation for people with disabilities.

The purpose of this study was to conduct a monostrand conversion mixed methods (Teddlie \& Tashakkori, 2006) examination of common digital entry points to undergraduate and graduate physics programs in the USA and to assess their accessibility. We chose to examine undergraduate curriculum webpages and graduate research webpages as they are common places students look for information about a physics program. Below, we summarize the basic principles of web accessibility and the related requirements (under USA law and policy) and responsibilities of organizations of higher education.

\section{Web accessibility principles}

The World Wide Web Consortium (W3C) is an international community that created a set of universally accepted accessibility guidelines known as the Web Content Accessibility Guidelines (WCAG). There have been multiple versions of the WCAG standards over time as webpages and coding languages evolve. Specifically, we employed the WCAG 2.0 standards instead of more recently developed versions (i.e., WCAG 2.1, which is the latest version since June 2018, or WCAG 2.2, which should be available in 2020) because accessibility evaluation software available at the time employed the WCAG 2.0 standards. 
WCAG organizes the basic principles of web accessibility into four categories, expressing web content should be perceivable, operable, understandable, and robust (Accessibility Principles, 2019). Perceivable web content provides multiple ways for users to access (e.g., visual, auditory) and customize (e.g., enlarge, change colors) information. Operable web content provides multiple ways to control (e.g., mouse, keyboard) and navigate (e.g., search boxes, site maps) webpages. Understandable web content is readable (e.g., identifies language), understandable (e.g., uses clear language), and helps users to avoid mistakes (e.g., provides error messages). Robust web content is compatible with multiple browsers and assistive technologies (e.g., alternate keyboards, screen readers). Further descriptions and examples of accessibility principles and practices for web content are provided in Appendix 1; this is not an exhaustive list.

Each principle is composed of guidelines which are each delineated by more specific "success criteria", which are rated on a three-level scale (A, AA, and AAA). The individual success criteria were assigned a level based on a number of interacting issues, including the impact of the success criterion on the accessibility of the content (e.g., a success criterion is essential if the content will be inaccessible even with assistive technology if the criterion is not met) and the difficulty of implementing the success criterion (e.g., the criterion requires skills that are reasonably achievable by content creators; World Wide Web Consortium, 2016). For example, the entries in Appendix 1 for guidelines 1.2 (Captions), 1.4 (Distinguishable), and 3.3 (Input assistance) demonstrate success criteria at all three levels of conformance.

\section{Accessibility requirements and responsibilities for higher education}

Inaccessible webpages limit access for individuals with disabilities. For example, poorly designed webpages create barriers for individuals with visual impairments (who may interact with the content via a screen reader), mobility impairments (who may navigate the webpage with a keyboard rather than a mouse), and attention disorders (who may use multiple means to navigate content efficiently).

\section{United States Federal Laws}

Section 508 of the Rehabilitation Act describes the online accessibility standards that federal agencies, contractors, and employers in the USA must meet (Rehabilitation Act, 1973). As of January 18, 2018, Section 508 requires that all federal information and communication technology services in the USA are compliant with WCAG 2.0 Level A and Level AA criteria. While American universities differ in their interpretations about whether Section 508 applies to them (LaGrow, 2017), all Title IV-participating institutions (those that award federal student loans) must maintain accessible websites under Section 504. Since Section 504 (Rehabilitation Act of 1973) does not explicate accessibility standards, Section 508 is generally accepted as the baseline for the federal government's expectations for accessibility (Straumsheim, 2017).

The Americans with Disabilities Act (ADA) of 1990 and the ADA Amendments Act (ADAA) of 2008 provides federal protections against discrimination for individuals with disabilities. Title II of the ADA extends discriminations protections to state and local government entities, which public postsecondary institutions are considered, while Title III of the ADA extends discrimination protections to places of public accommodation, which private postsecondary institutions are considered (Colker, 2016). Like Section 508, the ADA does not explicate accessibility standards. The WCAG 2.0 standards are typically used as accessibility standards in resolution agreements $^{2}$ reached between postsecondary institutions and the USA Department of Justice and the Department of Education.

\section{International laws}

There are many international laws that also cite the WCAG 2.0 standards. For example, Australia (Disability Discrimination Act, 1992), Canada (Policy on Communications and Federal Identity, 2016), the European Union (Web and Mobile Accessibility Direction, 2016), India (Guidelines for Indian Government Websites, 2009), and Israel (Equals Rights of Persons with Disabilities Act, 1998) all have accessibility laws that suggest or mandate WCAG compliance (World Wide Web Consortium, 2019a). However, a few countries have web accessibility laws that do not cite the WCAG standards (World Wide Web Consortium, 2019a), including Finland (Act on Electronic Services and Communication in the Public Sector, 2003), Japan (Basic Act on the Formation of an Advanced Information and Telecommunications Network Society, 2000), and Sweden (Discrimination Act, 2008). International laws vary in terms of their scope of applicability (i.e., public, private, or government sectors) and the level of success criteria of the WCAG standards they mandate compliance with (i.e., $\mathrm{A}$, AA, or AAA). Institutions of higher education

\footnotetext{
${ }^{2}$ Resolution agreements are settlement agreements where the subject institution agrees to certain obligations. Resolution agreements are created when a complaint filed with the Office of Civil Rights leads to a finding of discrimination. For example, see https://www.washington. edu/accessibility/requirements/accessibility-cases-and-settlementagreements/ or https://ocrcas.ed.gov/ocr-search.
} 
should be aware of and fluent with the web accessibility policies applicable in their country. Additionally, institutions that enroll students from other countries should be aware that these students come from countries that have different, and in some cases more stringent, web accessibility laws. Specifically, students originally from outside the $\mathrm{USA}^{3}$ represented $64 \%$ of all first-year physics graduate students at master's degree granting institutions and $56 \%$ at doctoral degree granting institutions in fall 2007 and fall 2009 combined (American Institute of Physics, 2012). Thus, most physics graduate students will be transitioning to universities in the USA and may experience different levels of access to physics department webpages due to differences in legal requirements of web accessibility across countries.

\section{Previous web accessibility studies in higher education}

In the last few decades, there have been multiple studies assessing the accessibility of higher education webpages in the USA (Floyd \& Santiago, 2007; Forgione-Barkas, 2012; Kimmons, 2017; Thompson et al., 2003; Thompson et al., 2010) and abroad (United Kingdom: Sloan et al., 2002; Malaysia: Aziz et al., 2010; Portugal: Gonçalves et al., 2013; Albania: Ferati et al., 2016; Kyrgyzstan, Azerbaijan, Kazakhstan, and Turkey: Ismailova \& Inal, 2018; Oceania and Arab countries: Alahmadi \& Drew, 2017). These investigations have spanned all levels of institutions of higher education including community colleges (Erickson et al., 2013), research institutions (McGough, 2016), and "top" international institutions (Kane et al., 2007).

These studies indicated that there are many accessibility errors present in institutional higher education webpages (i.e., there are many inaccessible components to higher education webpages). For example, Harper and DeWaters (2008) found that most university homepages in their study were not compliant with the WCAG 2.0 guidelines, and Forgione-Barkas (2012) found most errors in their study occurred within the Level-A conformance standards. Similarly, when Thompson et al. (2010) examined changes in web accessibility over a five-year period, they found "although significant positive gains regarding accessibility were revealed in some areas, such as alternate text on images and coded support for navigation, even in these areas the percentage of pages that are accessible is strikingly low" (p. 113).

Kimmons (2017) recently examined the homepages and first-level subpages of all institutions of higher

\footnotetext{
${ }^{3}$ Students originally from outside the USA are typically called "International Students". We purposefully do not use this language because it is America-centric.
}

education in the USA for compliance with web accessibility standards and found that $71.5 \%$ of institutions' homepages contained at least one error that would make it inaccessible, with an average of 5.89 errors per page. Kimmons (2017) states "website accessibility still seems to be a systemic struggle for institutions of higher education, as evidenced by the very high error rates present across homepages and subpages" (p. 447).

Noh et al. (2015) previously studied web accessibility of Korean science and technology institutions of higher education and found significant noncompliance with national laws related to web accessibility. Sixty-eight percent of websites complied with Perceivable guidelines, $64.5 \%$ complied with Operable guidelines, $59.2 \%$ complied with Understandable guidelines, and $28.0 \%$ complied with Robust guidelines.

The literature base suggests that many postsecondary institutions' webpages are not fully accessible for students with disabilities and may pose barriers to their full participation in the educational setting. The purpose of this study was to investigate the frequency and types of accessibility errors on USA webpages that prospective and current students would interact with when considering participation in a physics program.

\section{Research questions}

The research questions that guided our inquiry were:

1. To what extent are physics undergraduate curriculum and graduate research webpages accessible, as measured by alignment with WCAG 2.0 standards?

2. What are the frequent accessibility errors on physics undergraduate curriculum and graduate research webpages?

To answer these research questions, we employed a monostrand conversion mixed methods design (Teddlie \& Tashakkori, 2006). Specifically, this study is monostrand because we employed one line of inquiry, conversion because we quantified the WCAG error data collection for each webpage with descriptive statistics, and mixed methods because it included both qualitative (i.e., WCAG errors for each webpage) and quantitative data (i.e., frequency of specific errors occurring across webpages).

\section{Methodology \\ Sample}

We used the Integrated Postsecondary Education Data System (IPEDS) to locate every Title IV-participating postsecondary institution in the USA and created a 
random sample of 400 institutions using probability sampling (Tashakkori \& Teddlie, 2003). We included 400 institutions (approximately 6\%) by considering the overall population of Title IV-participating institutions $(N=6676)$. This is a sufficient sample for this study because we wanted to investigate common errors present in postsecondary education and not to investigate differences between types of institutions. Additionally, our sample size is aligned with standard sample sizes for probability sampling (Teddlie \& Yu, 2007). Because all the institutions in our sample were Title IVparticipating, they are mandated by Section 504 of the Rehabilitation Act (Rehabilitation Act of 1973) to meet the same accessibility guidelines as public institutions. We found that 74 of these 400 institutions offered physics degrees, including associate of arts (AA), associate of science (AS), bachelor of arts (BA), bachelor of science (BS), master of science (MS), and doctor of philosophy $(\mathrm{PhD})$. We did not include applied physics degrees, preservice physics teacher programs, or programs that had a physical science focus. We identified the hyperlink to the webpage with the university's physics degree requirements for each undergraduate degree offered (e.g., https://sciences.ucf.edu/physics/undergraduate/ curriculum/) and the graduate research opportunities (e.g., https://sciences.ucf.edu/physics/research/). Our final sample included 74 two-year and four-year institutions and 139 hyperlinks; the sample is summarized in Tables 1 and 2.

\section{Analysis}

We used Tenon $^{\text {TM }}$ accessibility software to analyze each undergraduate physics curriculum webpage and graduate research webpage in our sample for web accessibility on $1 / 22 / 2019$. Tenon ${ }^{\mathrm{Tm}}$ is a robust web accessibility audit software program capable of running nearly 100 total tests of web accessibility conforming to WCAG 2.0 Level-A, Level-AA, and Level-AAA standards (See the Web Accessibility Principles section of the Introduction for more information about the Levels; Tenon LLC, 2018). Tenon runs approximately 100 tests on each webpage to check for common errors and then aligns the error with the appropriate WCAG standards and levels. Tenon ${ }^{\mathrm{Tx}}$

Table 1 Institution webpage types included in our sample

\begin{tabular}{lll}
\hline Sector & Level & Institutions \\
\hline Public & 4-year & 27 \\
Public & 2-year & 20 \\
Private & 2-year & 26 \\
Private & 2-year & 1 \\
Total & & 74 \\
\hline
\end{tabular}

Table 2 Program webpage types included in our sample

\begin{tabular}{ll}
\hline Degree type & Programs \\
\hline Associate (AA and AS) & 31 \\
Bachelor of Arts & 34 \\
Bachelor of Science & 55 \\
Graduate Research (MS and PhD) & 19 \\
Total & 139 \\
\hline
\end{tabular}

reads the programming language in which a webpage is written (i.e., HTML) and then identifies errors (not warnings) in the programming language that alert content creators to the location of the error in the code and how to fix the error (Tenon LLC, 2020).

As Title IV participating institutions are not required to meet Level-AAA conformance, all Level-AAA errors identified in this study were removed from the analysis (Rehabilitation Act of 1973). Tenon ${ }^{\mathrm{Tm}}$ produces downloadable .csv reports which define the most prevalent web accessibility errors and the HTML location of the error. Comparative analyses of web accessibility evaluation software have found Tenon ${ }^{\mathrm{Tw}}$ to be an efficient, accurate, and robust web accessibility evaluation tool (Ismail et al., 2017; Taylor, 2018; Timbi-Sisalima et al., 2018). Tenon ${ }^{\text {th }}$ does not analyze PDF documents on webpages, so we did not analyze these webpages. Adobe Pro has an accessibility checker that can produce a report of accessibility errors present in a PDF document; however, the report is not aligned with the WCAG standards (Adobe, 2020).

The impact of a single accessibility error varies both by error type and end user. While a single error may not mean that the entire web page is inaccessible for all students (Erickson et al., 2013; Flowers et al., 2011; Hackett \& Parmanto, 2005; Thompson et al., 2010), a single error may mean that users with some disabilities may not be able to access the information on the web page. Thus, we also evaluated each webpage for web accessibility using Mac OS X's VoiceOver, which is a fully functional, robust, screen-reading assistive technology built-in to Apple computers and used by people with disabilities including blindness, low vision, and dyslexia. VoiceOver has been found to be a reliable, efficient, and effective assistive technology and was used to check the errors identified by Tenon to ensure the errors could reliably be identified through automatic and manual means. (Edwards, 2005; Henton, 2012; Manduchi \& Kurniawan, 2012). The research team selected VoiceOver instead of JAWS or another screen reader technology because the research team was familiar with VoiceOver and used Apple hardware, whereas JAWS runs on Windows. 
Specifically, the research team used VoiceOver's screen reading feature to start at the top of each webpage and move through each web element (e.g., hyperlink, image, video) including an error to explore whether the error was present and/or hindered access to information. The researcher controlled VoiceOver using the keyboard only and without any other form of input, such as a mouse or motion capture technology. As the researcher employed VoiceOver during the analysis, they used the Tenon report as a guide to ensure that all errors were verified and accurate. However, an important limitation of this study is that VoiceOver was the only assistive technology used in the auditing of the Tenon report and web accessibility of each webpage.

\section{Findings}

\section{Overall web accessibility}

Table 3 displays the mean, standard deviation, and high and low numbers of errors across the entire sample, by institution type and program type. In total, we identified 44,241 web accessibility errors across the 139 webpages. The webpage with the most accessibility errors included 1600 web accessibility errors; a VoiceOver audit of this webpage showed that every web element-all 1600-on this webpage was inaccessible for people who use screen readers. Tenon and VoiceOver audits of all the webpages in the sample indicated that only one physics curriculum webpage had minimal accessibility errors (i.e., 10 errors). The BS in physics curriculum webpage at this small, residential public university in the Southwest had only ten Level-A errors and no Level-AA errors. Our analysis with VoiceOver also indicated that a student with a disability could use VoiceOver and interact with every web element on the webpage without any missing information. However, Tenon has been criticized for being screen reader-centric, so other accessibility errors may be present (Clark, 2006).

\section{Most frequent web accessibility errors}

Table 4 displays the most frequent errors across the four categories of WCAG 2.0 identified in this study. This highlights the most abundant web accessibility errors in our sample and how postsecondary students with disabilities may be unduly burdened by certain types of errors if their disability requires a specific assistive technology (e.g., an assistive technology using a keyboard to input all information).

The data in Table 4 suggest that five Level-A and Level-AA errors were responsible for the majority of web accessibility errors in this study: non-text content (1.1.1); information and relationships (1.3.1); resize text (1.4.4); link purpose in context (2.4.4); and name, role, and value (4.1.2). Few errors were identified in the understandable category. Additionally, Appendix 2 shows the common error titles identified by Tenon aligned with the five most common WCAG 2.0 errors in our sample. We describe the common error and error titles below in the Discussion section.

Table 3 Descriptive statistics of web accessibility errors $(N=44,241)$ of physics curriculum webpages disaggregated by institution type and program type. Note: The cells are formatted as mean (standard deviation) with the high; low in the second line

\begin{tabular}{|c|c|c|c|}
\hline \multirow[t]{2}{*}{ Institution/program type } & \multicolumn{3}{|c|}{ Web accessibility errors } \\
\hline & Level A & Level AA & Levels A \& $A A^{a}$ \\
\hline All ( $N=73$ institutions) & $\begin{array}{l}296.3(288.5) \\
1556 ; 10\end{array}$ & $\begin{array}{l}36.2(27.2) \\
142 ; 0\end{array}$ & $\begin{array}{l}322.6(300.1) \\
1600 ; 10\end{array}$ \\
\hline Public, 4-year $\left(N=45^{b}\right)$ & $\begin{array}{l}246.4(181.4) \\
729 ; 10\end{array}$ & $\begin{array}{l}29.3(21.6) \\
100 ; 0\end{array}$ & $\begin{array}{l}275.7(187.1) \\
759 ; 10\end{array}$ \\
\hline Private, 4-year $(N=46)$ & $\begin{array}{l}302.1(315.4) \\
1556 ; 29\end{array}$ & $\begin{array}{l}38.1(22.8) \\
120 ; 7\end{array}$ & $\begin{array}{l}340.2(322.1) \\
1600 ; 48\end{array}$ \\
\hline Public, 2-year $(N=28)$ & $\begin{array}{l}341.9(353.2) \\
1412 ; 38\end{array}$ & $\begin{array}{l}41.2(33.5) \\
124 ; 5\end{array}$ & $\begin{array}{l}383.2(369.3) \\
1488 ; 43\end{array}$ \\
\hline Private, 2-year ( $N=2)$ & $\begin{array}{l}648.5(525.4) \\
1020 ; 277\end{array}$ & $\begin{array}{l}81.5(85.6) \\
142 ; 21\end{array}$ & $\begin{array}{l}730(610.9) \\
1162 ; 298\end{array}$ \\
\hline Associate's, AA and AS (N=33) & $\begin{array}{l}331.8(354.9) \\
1412 ; 38\end{array}$ & $\begin{array}{l}41.6(36.6) \\
142 ; 3\end{array}$ & $\begin{array}{l}373.4(377.4) \\
1488 ; 43\end{array}$ \\
\hline Bachelor's, BA and BS (N = 88) & $\begin{array}{l}283.1(260.4) \\
1556 ; 10\end{array}$ & $\begin{array}{l}34.3(22.6) \\
120 ; 0\end{array}$ & $\begin{array}{l}317.3(266.2) \\
1600 ; 10\end{array}$ \\
\hline Graduate research $(N=18)$ & $\begin{array}{l}191.6(166.8) \\
691 ; 25\end{array}$ & $\begin{array}{l}30.3(14.6) \\
61 ; 6\end{array}$ & $\begin{array}{l}221.9(167.5) \\
734 ; 57\end{array}$ \\
\hline
\end{tabular}

${ }^{a}$ Note: Only WCAG 2.0 Level-A and Level-AA errors were reported, as Section 508 only requires compliance with the Level-A and Level-AA web accessibility threshold

${ }^{\mathrm{b}}$ Note: All subsequent sample sizes refer to number of webpages. An individual institution may have multiple webpages in the sample 
Table 4 Descriptive statistics of web accessibility errors $(N=44,241)$ on physics curriculum webpages published on institutional webpages $(N=73)$, by error type

\begin{tabular}{|c|c|c|c|}
\hline \multicolumn{2}{|c|}{ Standards aligned with errors } & \multirow{2}{*}{$\frac{\text { Number of errors }}{17,564}$} & \multirow{2}{*}{$\frac{\% \text { of all error }}{39.7 \%}$} \\
\hline Perceivable & Level A, 1.3.1, Information and relationships & & \\
\hline & Level A, 1.1.1, Non-text content & 11,965 & $27.0 \%$ \\
\hline & Level AA, 1.4.4, Resize text & 4436 & $10.0 \%$ \\
\hline & Level A, 1.4.3, Contrast (minimum) & 413 & $<1 \%$ \\
\hline & Level A, 1.3.2, Meaningful sequence & 250 & $<1 \%$ \\
\hline & Level A, 1.2.2, Captions (prerecorded) & 1 & $<1 \%$ \\
\hline \multirow[t]{6}{*}{ Operable } & Level A, 2.4.4, Link purpose (in context) & 6514 & $14.7 \%$ \\
\hline & Level A, 2.1.1, Keyboard & 616 & $1.4 \%$ \\
\hline & Level A, 2.4.1, Bypass blocks & 118 & $<1 \%$ \\
\hline & Level AA, 2.4.6, Headings and labels & 88 & $<1 \%$ \\
\hline & Level A, 2.4.3, Focus order & 20 & $<1 \%$ \\
\hline & Level A, 2.4.2, Page titled & 2 & $<1 \%$ \\
\hline \multirow[t]{4}{*}{ Understandable } & Level A, 3.3.2, Labels or instructions & 1089 & $2.5 \%$ \\
\hline & Level A, 3.2.4, Consistent identification & 33 & $<1 \%$ \\
\hline & Level A, 3.2.1, On focus & 20 & $<1 \%$ \\
\hline & Level A, 3.1.1, Language of page & 14 & $<1 \%$ \\
\hline \multirow[t]{2}{*}{ Robust } & Level A, 4.1.2, Name, role, value & 4937 & $11.2 \%$ \\
\hline & Level A, 4.1.1, Parsing & 49 & $<1 \%$ \\
\hline Total & & 44,241 & \\
\hline
\end{tabular}

Note: 1 institution only had PDF webpages which cannot be analyzed using Tenon ${ }^{\text {TM }}$

\section{Discussion}

\section{Frequent perceivability errors and suggested corrections Common errors}

Level-A 1.3.1 information and relationships errors $(N=$ $17,564)$ comprised the largest percentage of all errors in this study (39.7\%). The W3C defines this guideline as "Information, structure, and relationships conveyed through presentation can be programmatically determined or are available in text" (Accessibility Principles, 2019). These errors are related to the underlying structure of the text on a webpage and whether students with a wide range of disabilities who use screen readers can easily understand the content. In our study, we identified three common error types Tenon identified as aligned with this guideline: implicit headings, all capitalized sentences, and multiple strategies used to create the labels. Implicit headings are sections of content that are bolded, possibly indicating a heading. Similarly, the second most common error aligned with this guideline was having large sections of text that are all capitalized. For example, many Level-A 1.3.1 errors identified web elements with overly long passages of text (ten or more words) in bold and/or uppercase letters. Although using bold and uppercase text may be beneficial for some web users, this formatting may be difficult to read and comprehend for students with dyslexia, for example. Sections of text that are bolded and/or in uppercase can imply a heading in the text. However, to interface with screen readers, HTML headings must be used.

Another common error aligned with WCAG Level A 1.3.1 was related to using multiple strategies to create labels. Specifically, multiple methods were used to create the same label on the webpage. For example, our sample included an institution whose associate's degree in physics curriculum webpage included a fillable form that used Cascading Style Sheets (CSS) to generate multiple labels for the fields within that form. CSS is generally used for defining the styling of a web page, such as colors and sizes of elements, but it also has the ability to insert content into the page. Either function has the possibility of creating accessibility barriers. Often, web developers will use visual elements to label form fields for sighted users and visually hidden HTML elements to label form fields for screen reader users. Having multiple labels for the same field allows opportunities for the labels to be repetitive or different from each other, since there are multiple places where the labels need to be updated, which could cause confusion for the user. In addition to 1.3.1, the multiple strategies to 
create labels error is aligned with standards 1.1.1, and 4.1.2. Many form fields are non-text, meaning that they need a text-based alternative, such as a form label, aligning with 1.1.1. For example, an empty form field (i.e., place for user to input information) does not have any text for the user; so, a form label can be added to inform the user how to interact with the web element. Also, form fields are user interface components (i.e., part of the webpage that the users interact with) and must adhere to all success criteria outlined in 4.1.2.

Level-A 1.1.1 non-text content errors $(N=11,965)$ comprised $27.0 \%$ of all web accessibility errors in this study. Non-text content errors occur when a non-text web element (e.g., image) is missing information to communicate with the assistive technology that a student with a disability may use to navigate the webpage. We identified three common error titles that Tenon aligned with this standard: the presence of non-text content created using cascading style sheets (CSS), uninformative text description of non-text information, and, similar to Level A 1.3.1, having multiple strategies to create a label.

Content styled with CSS can create accessibility issues for both sighted and screen reader users. For example, our sample included an institution whose bachelor's degree in physics curriculum webpage used CSS to generate content that appeared to be hyperlinked but was not. In this case, the CSS generated a word that was underlined but was not a hyperlink, possibly confusing students as to why the word was underlined or why it did not lead to a different webpage when underlined words in web content generally indicate hyperlinks. Additionally, many images were delivered via icon font, which may not be accessible via assistive technology. Thus, when screen reading software interacts with the non-text element, it reads the name of the font rather than a description of the content presented in the element.

Level-A 1.4.4 resize text errors $(N=4436)$ comprised $10.0 \%$ of all errors in this study. These errors pertain to the size and position of text on a webpage. Nearly all resize text errors in this study arose from font that was too small on the webpage for web users who have low vision. In some instances, the font on webpages was at 8 pixels or smaller, making it very difficult for most web users, and especially those with low vision, to read the text. The default font size in most web browsers is set to be 16 pixels. Another error Tenon aligned with this WCAG standard is that an element used absolute positioning. An element that is absolutely positioned can cause difficulties with zooming in on the webpage as the element has a set position rather than a position defined relative to another element on the webpage. If web users must zoom in to read the font, other content on the webpage may become distorted, leading to confusion.

\section{Suggested solutions}

Many of the Level-A 1.3.1 errors in this study could be fixed by adopting two approaches. First, using HTML to communicate headings rather than bold or uppercase text would improve the readability of text on the webpage. Second, explicit labels for each form field should be defined in HTML and then styled using CSS, accurately informing the user of what information belongs in the form field while achieving the desired design and avoiding duplicate form field labels. Writing appropriate HTML requires deeper knowledge of programming, so web administrators should be involved in this process.

Many of this study's Level-A 1.1.1 errors could be fixed by ensuring images and icons are presented with text-based equivalents and avoiding CSS-generated content. Level-A 1.4.4 errors could be fixed by increasing the size of webpage font and by using relative positioning of elements.

\section{Frequent operability errors and suggested corrections Common errors}

Level-A 2.4.4 link purpose web errors $(N=6514)$ comprised $14.7 \%$ of all web accessibility errors in this study. The W3C describes this standard as "The purpose of each link can be determined from the link text alone or from the link text together with its programmatically determined link context, except where the purpose of the link would be ambiguous to users in general" (Accessibility Principles, 2019).

Level-A 2.4.4 errors were identified for redundant hyperlink destinations with different hyperlink text, meaning hyperlinks with different link texts lead to the same webpage. Redundant hyperlink destinations may be confusing for students with disabilities, as a web user may expect that hyperlinks with different descriptive text lead to different webpages. Many other Level-A 2.4.4 errors identified uninformative hyperlink link texts (an informative description of the content pertaining to the hyperlink and where a user will go if they click on the hyperlink), including link text such as "link" and "link to page". These link texts are not informative enough for students with disabilities. For example, a student with low vision may navigate through a webpage using the tab key and may jump from one element type to another (e.g., links, buttons, form fields). When they land on a link, the link text will be read out loud. If the link text is informative, the link will make sense without the user having to explore the surrounding text for 
context. Instead, content editors should provide rich link texts of hyperlinks (e.g., "physics curriculum webpage" instead of "link"), so that students with disabilities are given enough information to successfully navigate the webpage and find the content they need.

\section{Suggested solutions}

Many of the Level-A 2.4.4 errors could be resolved by making sure that all hyperlinks include unique, informative link texts and that multiple hyperlinks with differing link texts do not lead to the same webpage. As a result, users will know exactly what content the hyperlink pertains to and exactly where the hyperlink will lead them when clicked.

\section{Frequent robustness errors and suggested corrections Common error}

Robust Level-A 4.1.2 name, role, and value errors were abundant $(N=4937)$ and comprised $11.2 \%$ of all web accessibility errors in this study. The W3C states that the intent of Level-A 4.1.2 is to "ensure that Assistive Technologies (AT) can gather information about, activate (or set) and keep up to date on the status of user interface controls in the content" (Accessibility Principles, 2019). Errors in our study that aligned with this success criterion were related to a webpage having an invalid hypertext reference and related to orphaned Accessible Rich Internet Application (ARIA) attributes. Href stands for "hypertext reference" and is information that specifies the URL of the webpage that the hyperlink goes to. This likely corresponds to a webpage including a link to scroll to the top of the webpage rather than to redirect to another webpage (i.e., HTML that reads href="\#"). This type of href makes the link confusing when interfacing with the webpage via an assistive technology. In addition, many Level-A 4.1.2 errors identified "orphaned" ARIA attributes. ARIA attributes are additional pieces of information that communicate with assistive technologies, informing the user about what kind of web elements are on the webpage and how to interact with the elements. In this case, "orphaned" ARIA attributes are attributes that depend on a previously defined ARIA attribute or parent attribute; however, the parent attribute does not exist.

Both href and ARIA attributes of hyperlinks are important when a wide range of assistive technologies attempt to communicate with web elements on a webpage and they mark up the webpage to give cues to the user about the interface. Additional information about when to use and not use ARIA attributes is described by the W3C (World Wide Web Consortium, 2018). However, the W3C states: "no ARIA is better than bad ARIA" (World Wide Web
Consortium, 2019c) so the implementation of ARIA in a webpage should be done in concert with webpage design experts.

\section{Suggested solution}

Level-A 4.1.2 errors require more extensive knowledge of markup language (e.g., HTML, JavaScript), so they should be addressed by web administrators and developers working at institutions of higher education to ensure that each institutional webpage includes the most robust and informative information to allow the widest range of assistive technologies access to the content. As Level-A 4.1.2 errors primarily address content developed by the web administrator, these errors are most prevalent when web elements are developed but under described, such as the case of missing href or ARIA attributes. It takes more technical skill to accessibly generate complicated web elements; thus, physics departments should strive to create webpages using simple web elements.

\section{Other errors with simple solutions}

One perceivable Level-A 1.2.2 captions (prerecorded) error was identified in this study. This error indicates that a video was not captioned, making it difficult for web users who are deaf to access the content (e.g., requiring them to use additional resources, such as a sign language interpreter). All video content should be captioned.

Understandable Level-A 3.1.1 language of page errors $(<1 \%$ of all errors) indicate that the spoken language of the webpage (i.e., "en" for English) was not included in the language attributes of the web element. In this case, a screen reader interfacing with the webpage will not know what language it is reading and may mispronounce words. Moreover, a student with a disability who is an English language learner may not be aware that the webpage contains multilingual content. The language used on a webpage should be identified in the attributes of the web element.

Operable Level-A 2.1.1 keyboard errors (1.4\% of all errors) indicate that many web elements were not written in ways that allow keyboard-centric assistive technologies access to the content. For example, some users exclusively use a keyboard to navigate a webpage while others use alternative keyboards. Although Level-A 2.1.1 errors involve many different aspects of web accessibility, it is important to note that keyboardcentric assistive technologies are widely used by people with disabilities when accessing webpages. Physics curriculum writers and institutional web developers should pay close attention to whether their webpages can be used with a keyboard alone without requiring the use of a mouse. Professionals interested in improving the web 
accessibility of their webpages could look to WebAIM's website, published specifically to educate people who wish to improve their web accessibility and provide more inclusive and robust online information for people with disabilities.

Overall, the findings of this study are in line with findings from previous studies. Specifically, many web pages in higher education do not align with the WCAG guidelines (Erickson et al., 2013; Forgione-Barkas, 2012; Kimmons, 2017; Solovieva \& Bock, 2014; Thompson et al., 2010). Multiple studies similarly identified a significant lack of meaningful description for images (Hackett \& Parmanto, 2005; Krach, 2007; Thompson et al., 2010) which aligns with our finding of many 1.1.1 Level-A errors. Prior investigations (see McGough, 2016 for a summary) also identified accessibility issues related to skip navigation and effective keyboard navigation. These two issues were not commonly identified as errors in this study.

\section{Limitations}

This study focused on one facet of accessibility present in the postsecondary learning environment (i.e., web accessibility). However, there are multiple aspects related to accessibility that were beyond the scope of this study, including (1) the accessibility of physics curricular content (which we previously investigated in Scanlon et al., 2018b); (2) on-campus living space; (3) the social interactions between students with disabilities and their instructors and peers (which we previously investigated in James et al., 2019); (4) the relationship between the local disability services office, instructors, and students with disabilities; and (5) attitudes and beliefs of instructors and university staff (which we previously investigated in Scanlon \& Chini, 2019). All aspects of accessibility can affect how a student with disability interacts with the learning environment and their success in the program of their choice.

This monostrand conversion mixed methods study focused only on webpages in the USA related to undergraduate physics curriculum and graduate research opportunities, and our sample did not include any private, for-profit institutions. Additionally, our sample was limited to $6 \%$ of title IV-participating institution in the USA.

Moreover, this study was limited by the evaluation of web accessibility using a single accessibility audit software and one assistive technology. The WCAG standards have been criticized for being screen readercentric and for not including success criteria for people with cognitive impairments (Clark, 2006). More information about the work the $\mathrm{W} 3 \mathrm{C}$ is doing to support people with cognitive impairments for next iterations of the WCAG standards can be found on their website (World Wide Web Consortium, 2019b). In addition, the chosen accessibility audit software did not check for time-based media (i.e., audio or video) described in WCAG 2.0 Standard 1.2. Because our analysis and proposed suggestions are aligned with specific WCAG 2.0 standards, our proposed suggestions will be similarly screen readercentric. Given the time-intensive nature of data collection and analysis, the research team decided it was only feasible to evaluate the webpages using one audit software and one assistive technology, understanding that webpages often change on a daily or hourly basis. In addition, this study only analyzed HTML content of webpages and not other documents, such as PDF files or PowerPoint presentations.

As a result, future research could expand upon our sample size, use a greater number of accessibility audit software programs and assistive technologies, audit specific courses in physics curriculum, expand the number of WCAG standards investigated, and employ a larger research team to provide a more comprehensive picture of the web accessibility of physics curriculum webpages at US institutions of higher education. Additionally, future research could address other webpages students must interact with to navigate postsecondary education, such as financial aid, student affairs, and Title-IX webpages.

\section{Conclusions and implications}

Below, we explicate the implications of our study for four groups of stakeholders: instructors, university administrators, the broader physics community, and physics students.

\section{Implications for physics instructors and staff}

Depending on institutional norms, physics instructors and support staff may be responsible for creating web content and editing course webpages via a learning management system and/or may collaborate with information technology staff on institutional and departmental webpages. In either case, physics instructors and staff should be aware of the technological hurdles that students with disabilities face when accessing online content and should explore alternative ways of delivering content to students with disabilities to ensure that all students have access to physics curricula and other learning materials. Instructors and staff should also be aware that students with disabilities will need to contact them individually to get access to relevant information and should be ready and eager to provide this information to any student who asks for it. Bradbard and Peters (2010) provide an introduction to web accessibility for faculty, and Amundson (2009) provides five steps for instructors to increase the accessibility of their webpages. 
McGough (2016) found that institutions will not make changes to make their webpages more accessible unless there are outside pressures, such as lawsuits. Thus, faculty have a role to play in moving the university toward being more inclusive. Challenging the status quo comes with risk, so faculty with more positional power (e.g., tenured or permanent faculty) should use their power to advocate for the university administration to proactively create webpages and content that are accessible to all students to be in compliance with federal law and to be anti-ableist. All faculty can also work to increase their knowledge of and expertise in supporting people with disabilities more broadly by partnering with their local special education, exceptional education, and/or disability studies departments.

Implications for university administrators and institutional leaders

Advances in technology have rendered the Internet and postsecondary webpages essential resources for all educational stakeholders, including students. However, advances in technology bring challenges when crafting online content that is truly accessible to all students, not just those without physical, developmental, or cognitive limitations.

Institutions of higher education have faced hundreds of disability-related lawsuits brought by people who were not able to have equitable access to educational opportunity online. If institutional leaders want to support all students and increase access to their institution, web accessibility must be prioritized. Moreover, research tells us that students with disabilities are underrepresented in STEM degree programs and the STEM workforce (NSF, 2019). Improvements in web accessibility would not only help avoid costly litigation, but more importantly would increase access to STEM-major information for students with disabilities. Also, if an institution's webpages are noticeably more accessible than another institution's, then students with disabilities would be more likely to enroll at the more accessible institution (Burdett, 2013; Daun-Barnett \& Das, 2013). Burgstahler (2006) and Tandy and Meacham (2009) provided suggestions for administrators on how to increase the accessibility of their institution's webpages. Individuals can investigate the accessibility of webpages using WebAIM's WAVE tool (https://webaim.org/).

\section{Implications for the broader physics community}

The broader physics community needs to recognize that we have a significant problem with the accessibility of our webpages. If we want to increase the representation of people with disabilities in physics and, more broadly, the diversity of the physics community, then we need to increase accessibility. Creating accessible web content should be a priority for the physics community. If we do not create accessible webpages, we send the message that we do not expect people with disabilities to participate in our community. We must continue to include disability as a dimension of diversity that we care about.

To increase the accessibility of physics webpages, we need to provide instructors, faculty, staff, and non-profit leaders with support (financial, intellectual, and moral) to press universities and organizations to make changes toward accessibility. For example, professional societies (e.g., American Physical Society (APS) or Institute of Physics (IOP) in physics) could maintain "tips and tricks" for creating accessible web content and could include accessibility checks in recommendations for program review.

\section{Implications for current and prospective physics students with disabilities}

While students are not responsible for making physics program webpages more accessible, current and prospective physics students with disabilities need to be aware that physics webpages had many web accessibility errors and can create barriers to their participation in physics. As such, students should be ready to advocate for themselves to get access to information they need. They should also be open to communicating directly with institutional faculty and staff. The University of Washington Disabilities, Opportunities, Internetworking, and Technology (DO-IT) network provides a myriad of resources for students with disabilities.

\section{Conclusions}

Through analysis of undergraduate physics curriculum and graduate physics research webpages, we found that 138 out of 139 webpages had numerous accessibility errors. The most common of these errors were related to information, structure, and relationships of content (1.3.1 Level A; 39.7\%); text alternatives for non-text content (1.1.1 Level A; 27.0\%); information about link purpose (2.4.4 Level A; 14.7\%); capability to resize text (1.4.4 Level AA; 10.0\%); and information about the name, role, and value of user interface components (4.1.2 Level A; 11.2\%). Stakeholders at all levels of postsecondary education, including individual students, faculty, instructors, staff, administrators, and the broader physics community, all have a role to play in increasing the accessibility of physics webpages. If we want to support the participation of people with disabilities in physics, then we must move toward increasing the accessibility of physics webpages. 


\section{Appendix 1}

\section{Descriptions and examples of accessibility principles and practices for web content}

Table 5 Web Content Accessibility Guidelines (WCAG) principles, guidelines, and examples of success criteria and their levels (Note: this is not an exhaustive list)

\begin{tabular}{ll}
\hline Principles & Guidelines \\
\hline $\begin{array}{l}\text { 1. Perceivable } \\
\text { information and user } \\
\text { interface }\end{array}$ & 1.1 Text alternatives for non-text content \\
& \\
& $\begin{array}{l}1.2 \text { Captions and other alternatives for } \\
\text { multimedia }\end{array}$
\end{tabular}
multimedia

1.3 Adaptable: content can be presented in different ways without losing information or structure

4 Distinguishable: content is easier to see and hear

2.1 Keyboard accessible: Functionality is

2. Operable user available from a keyboard

2.2 Enough time: Users have enough time to read and use the content

2.3 Seizures: Content does not cause seizures

\section{Example success criteria}

1.1.1 Non-text content: All non-text content that is presented to the user has a text alternative that serves the equivalent purpose except for a short list of exceptions with individual success criteria (e.g., If non-text content is a control or accepts user input, then it has a name that describes its purpose.)

(Level A)

1.2.2 Captions (prerecorded): Captions are provided for all prerecorded audio content in synchronized media, except when the media is a media alternative for text and is clearly labeled as such. (Level A) 1.2.5 Audio description (prerecorded): Audio description is provided for all prerecorded video content in synchronized media. (Level AA) 1.2.6 Sign language (prerecorded): Sign language interpretation is provided for all prerecorded audio content in synchronized media. (Level AAA)

1.3.1 Info and relationships: Information, structure, and relationships conveyed through presentation can be programmatically determined or are available as text (Level $\mathbf{A}$ )

1.3.2 Meaningful sequence: When the sequence in which content is presented affects its meaning, a correct reading sequence can be programmatically determined. (Level A)

1.3.3 Sensory characteristics: Instructions provided for understanding and operating content do not rely solely on sensory characteristics of components such as shape, size, visual location, orientation, or sound. (Level A)

1.4.1 Use of color: Color is not used as the only visual means of conveying information, indicating an action, prompting a response, or distinguishing a visual element. (Level A)

1.4.3 Contrast (minimum): The visual presentation of text and images of text has a contrast of at least 4.5:1, except for large-scale text, incidental text (e.g., pure decoration), and logotypes. (Level AA)

1.4.4 Resize text: Except for captions and images of text, text can be resized without assistive technology up to $200 \%$ without loss of content or functionality. (Level AA)

1.4.9 Images of text (no exception): Images of text are only used for pure decoration or where a particular presentation of text is essential to the information being conveyed. (Level AAA)

2.1.1 Keyboard: All functionality of the content that is operable through a keyboard interface without requiring specific timings for individual keystrokes, except where the underlying function requires input that depends on the path of the user's movement and not just the end points. (Level A)

2.1.2 No keyboard trap: If keyboard focus can be moved to a component of the page using a keyboard interface, then focus can be moved away from that component using only a keyboard interface, and, if it requires more than unmodified arrow or tab keys or other standard exit methods, the user is advised of the method for moving focus away. (Level A)

2.2.2 Pause, stop, hide: For moving, blinking, scrolling, or auto-updating information, all of the following are true: (1) starts automatically, (2) lasts more than $5 \mathrm{~s}$, and (3) is presented in parallel with other content, there is a mechanism for the user to pause, stop, or hide it unless the movement, blinking, or scrolling is part of an activity where it is essential.

(Level A)

2.2.5 Re-authenticating: When an authenticated session expires, the user can continue the activity without loss of data after re-authenticating. (Level AAA)

2.3.1 Three flashes or below threshold: Webpages do not contain anything that flashes more than three times in any 1-s period, or the flash is below the general flash and red flash thresholds. (Level A)

2.3.2 Three flashes: Webpages do not contain anything that flashes more than three times in any 1-s period. (Level AAA) 
Table 5 Web Content Accessibility Guidelines (WCAG) principles, guidelines, and examples of success criteria and their levels (Note: this is not an exhaustive list) (Continued)

\begin{tabular}{|c|c|c|}
\hline Principles & Guidelines & Example success criteria \\
\hline & $\begin{array}{l}2.4 \text { Navigable: Users can easily navigate, find } \\
\text { content, and determine where they are on a } \\
\text { webpage }\end{array}$ & $\begin{array}{l}\text { 2.4.1 Bypass blocks: A mechanism is available to bypass blocks of content } \\
\text { that are repeated on multiple webpages. (Level A) } \\
\text { 2.4.2 Page titled: Webpages have titles that describe topic or purpose. } \\
\text { (Level A) } \\
\text { 2.4.3 Focus order: If a webpage can be navigated sequentially and the } \\
\text { navigation sequences affect meaning or operation, focusable } \\
\text { components receive focus in an order that preserves meaning and } \\
\text { operability. (Level } \mathbf{A} \text { ) } \\
\text { 2.4.4 Link purpose (in context): The purpose of each link can be } \\
\text { determined from the link text alone or from the link text together with } \\
\text { its programmatically determined link context, except where the purpose } \\
\text { of the link would be ambiguous to users in general. (Level } \mathbf{A} \text { ) } \\
\text { 2.4.6 Headings and labels: Headings and labels describe topic or purpose. } \\
\text { (Level AA) }\end{array}$ \\
\hline
\end{tabular}

3. Understandable information and user interface
3.1 Readable: Text is readable and understandable

3.1.1 Language of page: The default human language of each webpage can be programmatically determined. (Level A)

3.1.3 Unusual words: A mechanism is available for identifying specific definitions of words or phrases used in an unusual or restricted way, including idioms and jargon. (Level AAA)

3.1.4 Abbreviations: A mechanism for identifying the expanded form of meaning of abbreviations is available. (Level AAA)

3.2 Predictable: Content appears and operates in 3.2.1 On focus: When any component receives focus, it does not initiate predictable ways

a change of context.

\section{(Level A)}

3.2.2 On input: Changing the setting of any user interface component does not automatically cause a change of context unless the user has been advised of the behavior before using the component. (Level $\mathbf{A}$ ) 3.2.4 Consistent identification: Components that have the same functionality within a set of webpages are identified consistently. (Level AA)

3.3 Input assistance: Users are helped to avoid and correct mistakes

3.3.1 Error identification: If an input error is automatically detected, the item that is in error is identified and the error is described to the user in text. (Level A)

3.3.2 Labels or instructions: Labels or instructions are provided when content requires user input. (Level A)

3.3.3 Error suggestion: If an input error is automatically detected and suggestions for the correction are known, then the suggestions are provided to the user, unless it would jeopardize the security or purpose of the content. (Level AA)

3.3.6 Error prevention (all): For webpages that require the user to submit information, at least of the following is true: (1) Reversible: Submissions are reversible. (2) Checked: Data entered by the user is checked for input errors and the user is provided an opportunity to correct them. (3) Confirmed: A mechanism is available for reviewing, confirming, and correcting information before finalizing the submission. (Level AAA)

4.1.1. Parsing: In content implemented using markup languages, elements have complete start and end tags, elements are nested according to their specifications, elements do not contain duplicate attributes, and any IDs are unique, except where the specifications allow these features. (Level A)

4.1.2 Name, role, value: For all user interface components, the name and role can be programmatically determined; states, properties, and values that can be set by the user can be programmatically set; and notification of changes to these items is available to user agents, including assistive technologies. (Level A) 


\section{Appendix 2}

\section{Commonly identified errors from Tenon and their error titles}

Table 6 Most common error titles identified by Tenon aligned with the most common WCAG errors for this sample. Only error titles that comprised at least 5\% of the errors within a particular WCAG success criteria are presented here

\begin{tabular}{|c|c|c|c|}
\hline WCAG 2.0 success criteria & Error title & \# of errors & $\%$ of error type \\
\hline \multirow[t]{3}{*}{ Level A, 1.1.1, Non-text content } & CSS-generated content found & 7589 & $63.4 \%$ \\
\hline & This icon font has no accessible name & 2654 & $22.2 \%$ \\
\hline & This element uses multiple strategies to create labels & 1038 & $8.7 \%$ \\
\hline \multirow[t]{3}{*}{ Level A, 1.3.1, Info and relationships } & This may be an implicit heading. & 8409 & $47.9 \%$ \\
\hline & All caps text found & 4995 & $28.4 \%$ \\
\hline & This element uses multiple strategies to create labels & 1038 & $5.9 \%$ \\
\hline \multirow[t]{2}{*}{ Level AA, 1.4.4, Resize text } & This element uses absolute positioning & 3319 & $74.8 \%$ \\
\hline & Very small text found & 1101 & $24.8 \%$ \\
\hline \multirow[t]{4}{*}{ Level A, 2.4.4, Link purpose (in context) } & Links have identical 'href' attribute values but different text & 2311 & $35.5 \%$ \\
\hline & This link has a 'title' attribute that is the same as the text inside the link & 1904 & $29.2 \%$ \\
\hline & Links have the same text but different destinations & 1629 & $25.0 \%$ \\
\hline & This link has no text inside it & 517 & $7.9 \%$ \\
\hline \multirow[t]{3}{*}{ Level A, 4.1.2, Name, role, value } & This link uses an invalid hypertext reference. & 1639 & $33.2 \%$ \\
\hline & Element has orphaned aria attributes & 1264 & $25.6 \%$ \\
\hline & This element uses multiple strategies to create labels & 1038 & $21.0 \%$ \\
\hline
\end{tabular}

\begin{abstract}
Abbreviations
ARIA: Accessible Rich Internet Applications; CSS: Cascading Style Sheets; HREF: Hypertext reference; HTML: Hypertext markup language; IPEDS: Integrated Postsecondary Education Data System; NSF: National Science Foundation; STEM: Science, Technology, Engineering, and Mathematics; USA: United States of American; W3C: World Wide Web Consortium; WCAG: Web Content Accessibility Guidelines
\end{abstract}

\section{Acknowledgements}

Not applicable

\section{Authors' contributions}

ZWT, ES, and JCC coordinated to conceive and conduct this study. ZWT conducted the Tenon and VoiceOver analysis, while ES, JR, and JB interpreted the findings for the STEM community. The authors contributed to writing, read, and approved the final manuscript.

\section{Funding}

This work is supported in part by National Science Foundation award \# 1750515

\section{Availability of data and materials}

The dataset supporting the conclusions of this article are available from the authors upon request.

\section{Declarations}

\section{Competing interests}

The authors declare that they have no competing interests.

\section{Author details}

${ }^{1}$ Department of Physics, University of Central Florida, Orlando, FL, USA. 2Department of Physics, University of Connecticut, Groton, CT, USA. ${ }^{3}$ Department of Educational Leadership and Policy, University of Texas at Austin, Austin, TX, USA. ${ }^{4}$ Center for Distributed Learning, University of Central Florida, Orlando, FL, USA.
Received: 17 August 2020 Accepted: 22 February 2021

Published online: 02 April 2021

\section{References}

Accessibility Principles. (2019). Retrieved from https://www.w3.org/WAl/funda mentals/accessibility-principles/.

Act on Electronic Services and Communication in the Public Sector of 2003 (2003). Retrieved from https://finlex.fi/en/laki/kaannokset/2003/en20030013.pdf.

Adobe. (2020). Determine how easily persons with disabilities can access PDF documents with the Adobe Acrobat Pro DC Accessibility Checker. Retrieved from https://www.adobe.com/accessibility/products/acrobat/using-acrobatpro-accessibility-checker.html.

Alahmadi, T., \& Drew, S. (2017). Accessibility evaluation of top-ranking university websites in World, Oceania, and Arab categories for home, admission, and course description webpages. Journal of Open, Flexible and Distance Learning, 21(1), 7-24.

American Institute of Physics. (2012). Characteristics of first-year physics graduate students in the U.S. by highest degree awarded by department, fall 2007 and fall 2009 combined. Retrieved from https://www.aip.org/statistics/data-gra phics/characteristics-first-year-physics-graduate-students-us-highest-degree.

Amundson, L. (2009). Five steps to an accessible classroom website. Learning \& Leading with Technology, 37(3), 16-19.

Aziz, M. A. Isa, W. A. R. W. M. \& Nordin, N. (2010). Assessing the accessibility and usability of Malaysia higher education website. In International Conference on User Science and Engineering (i-USEr), (p. 11836019). https://doi.org/10.1109/ IUSER.2010.5716752.

Basic Act on the Formation of an Advanced Information and Telecommunications Network Society of (2000). Retrieved from http://japan.kantei.go.jp/it/it_basicla w/it_basiclaw.html.

Berne, P., Morales, A. L., Langstaff, D., \& Invalid, S. (2018). Ten principles of disability justice. WSQ: Women's Studies Quarterly, 46(1), 227-230.

Bittinger, J. (2018). STEM pipeline for students with disabilities: From high school to intentions to major in STEM. Unpublished dissertation. Retrieved from https:// scholarworks.umass.edu/cgi/viewcontent.cgi?article=2293\&context=disserta tions_2.

Bradbard, D. A., \& Peters, C. (2010). Web accessibility theory and practice: an introduction for university faculty. Journal of Educators Online, 7(1). 
Burdett, K. R. (2013). How students choose a college: Understanding the role of internet based resources in the college choice process. Unpublished dissertation. Retrieved from https://digitalcommons.unl.edu/cgi/viewcontent. cgi? article $=1158 \&$ context $=$ cehsedaddiss.

Burgstahler, S. (2006). Web accessibility: guidelines for busy administrators. Handbook of Business Strategy, 7(1), 313-318. https://doi.org/10.1108/1077573 0610618990

Clark, J. (2006). To hell with the WCAG 2. a list apart. https://alistapart.com/article/ tohellwithwcag2/.

Colker, R. (2016). Federal disability law in a nutshell (West nutshell series). St. Paul: West Academic.

Daun-Barnett, N., \& Das, D. (2013). Unlocking the potential of the Internet to improve college choice: A comparative case study of college-access Web tools. Journal of Marketing for Higher Education, 23(1), 113-134. https://doi. org/10.1080/08841241.2013.805708.

Disability Discrimination Act of 1992 (1992). Retrieved from https://www.legisla tion.gov.au/Details/C2016C00763.

Disability Discrimination Act of 2008 (2008). Retrieved from https://www. government.se/information-material/2015/09/discrimination-act-2008567/.

Edwards, P. (2005). A new era for technology. The Braille Forum, 44(2), 9.

Equals Rights of Persons with Disabilities Act of 1998 (1998). Retrieved from https://www.justice.gov.l//En/Units/CommissionEqualRightsPersonsDisa bilities/Equal-Rights-For-Persons-With-Disabilities-Law/Pages/Equal-Rights-ForPersons-With-Disabilities-Law.aspx.

Erickson, W., Trerise, S., Lee, C., VanLooy, S., Knowlton, S., \& Bruyère, S. (2013). The accessibility and usability of college websites: is your website presenting barriers to potential students? Community College Journal of Research and Practice, 37(11), 864-876. https://doi.org/10.1080/10668926.2010.484772.

Ferati, M., Mripa, N., \& Bunjaku, R. (2016). Accessibility of MOOCs for blind people in developing non-English speaking countries. In Advances in design for inclusion, (pp. 519-528). Cham: Springer.

Flowers, C., Bray, M., \& Algozzine, R. F. (2011). Content accessibility of community college websites. Community College Journal of Research and Practice, 25(7), 475-485. https://doi.org/10.1080/10668920152407874

Floyd, K. S., \& Santiago, J. (2007). The state of website accessibility in higher education. SAIS 2007 Proceedings. Retrieved from https://aisel.aisnet.org/cgi/ viewcontent.cgi?article $=1019 \&$ context=sais2007.

Forgione-Barkas, E. (2012). Postsecondary web accessibility for students with disabilities: a collective case study. Unpublished dissertation. Retrieved from https://search.proquest.com/docview/1347646553?pq-origsite=gscholar.

Gonçalves, R., Martins, J. L. B. R., Pereira, J., \& Cota, M. P. (2013). Can I access my school website? Auditing accessibility of the Portuguese teaching institutions websites. Journal of Universal Computer Science, 19(18), 2639-2655. https:// doi.org/10.3217/jucs-019-18-2639.

Guidelines for Indian Government Websites (2009). Retrieved from https://web. guidelines.gov.in/.

Hackett, S., \& Parmanto, B. (2005). A longitudinal evaluation of accessibility: higher education web sites. Internet Research, 15(3), 281-294. https://doi.org/10.11 08/10662240510602690.

Harper, K. A., \& DeWaters, J. (2008). A quest for website accessibility in higher education institutions. The Internet and Higher Education, 11(3-4), 160-164. https://doi.org/10.1016/j.iheduc.2008.06.007.

Henton, C. (2012). Text-to-speech synthesis development. The Encyclopedia of Applied Linguistics. https://doi.org/10.1002/9781405198431.wbeal1207.

Ismail, A., Kuppusamy, K. S., \& Nengroo, A. S. (2017). Multi-tool accessibility assessment of government department websites: a case-study with JKGAD. Disability and Rehabilitation. Assistive Technology, 13(6), 504-516. https://doi. org/10.1080/17483107.2017.1344883.

Ismailova, R., \& Inal, Y. (2018). Accessibility evaluation of top university websites: A comparative study of Kyrgyzstan, Azerbaijan, Kazakhstan and Turkey. Universal Access in the Information Society, 17(2), 437-445. https://doi.org/10.1007/s102 09-017-0541-0

James, W., Lamons, K., Spilka, R., Bustamante, C., Scanlon, E., \& Chini, J. J. (2019). Hidden walls: STEM course barriers identified by students with disabilities, 2019 PERC Proceedings. https://doi.org/10.1119/perc.2019.pr.James

Kane, S., Shulman, J., Shockley, T., \& Ladner, R. (2007). A web accessibility report card for top international university web sites. In Proceedings of the International Cross-disciplinary Conference on Web Accessibility (W4A), (pp. 148-156).

Kimmons, R. (2017). Open to all? Nationwide evaluation of high-priority web accessibility considerations among higher education websites. Journal of
Computing in Higher Education, 29(3), 434-450. https://doi.org/10.1007/s1252 8-017-9151-3.

Krach, S. K. (2007). Snapshot - ten years after the law: a survey of the current status of university web accessibility. Journal of Special Education Technology, 22(4), 30-40.

Kurth, N., \& Mellard, D. (2006). Student perceptions of the accommodation process in postsecondary education. Journal of Postsecondary Education and Disability, 19(1), 71-84.

LaGrow, M. (2017). The section 508 refresh and what it means for higher education. EDUCAUSE Review. Retrieved from https://er.educause.edu/a rticles/2017/12/the-section-508-refresh-and-what-it-means-for-higher-educa tion.

Love, T. S., Kreiser, N., Camargo, E., Grubbs, M. E., Kim, E. J., Burge, P. L., \& Culver, S. M. (2014). STEM faculty experiences with students with disabilities at a Land Grant Institution. Journal of Education and Training Studies, 3(1), 27-38. https://doi.org/10.11114/jets.v3i1.573.

Manduchi, R., \& Kurniawan, S. (2012). Assistive technology for blindness and low vision. Boca Raton: Taylor \& Francis.

McGough, J. D. (2016). Website accessibility compliance at research institutions. Unpublished dissertation (Central Washington University). Retrieved from https://digitalcommons.cwu.edu/cgi/viewcontent.cgi?article=1373\&context=etd.

Moriarty, M. A. (2007). Inclusive pedagogy: Teaching methodologies to reach diverse learners in science instruction. Equity \& Excellence in Education, 40(3), 252-265. https://doi.org/10.1080/10665680701434353.

National Center for Education Statistics (NCES). (2016). National postsecondary student aid study. Retrieved from https://nces.ed.gov/surveys/npsas/pdf/N16_ Data_Info.pdf.

National Center for Education Statistics (NCES). (2019). Profile of undergraduate students: attendance, distance and remedial education, degree program and field of study, demographics, financial aid, financial literacy, employment and military status: 2015-2016. Retrieved from https://nces.ed.gov/pubsearch/ pubsinfo.asp?pubid=2019467.

National Center for Science and Engineering Statistics (NCSES). (2015). Women, minorities, and persons with disabilities in science and engineering: 2015. Arlington: National Center for Science and Engineering Statistics Retrieved from http://www.nsf.gov/statistics/wmpd/.

National Science Foundation (NSF) (2011). Empowering the nation through discovery and innovation: NSF strategic plan for fiscal years 2011-2016. Washington, DC: National Science Foundation.

National Science Foundation (NSF), National Center for Science and Engineering Statistics (2019). Women, minorities, and persons with disabilities in science and engineering: 2019. Alexandria: National Science Foundation, National Center for Science and Engineering Statistics Retrieved from https://www.nsf.gov/sta tistics/wmpd.

Noh, K., Jeong, E., You, Y., Moon, S., \& Kang, M. (2015). A study on the current status and strategies for improvement of web accessibility compliance of public institutions. Journal of Open Innovation: Technology, Market, and Complexity, 1(1), 4. https://doi.org/10.1186/s40852-015-0001-0.

Policy on Communications and Federal Identity (2016). Retrieved from https:// www.tbs-sct.gc.ca/pol/doc-eng.aspx?id=30683.

Raue, K., \& Lewis, L. (2011). Students with disabilities at degree-granting postsecondary institutions (NCES 2011-018), U.S. Department of Education, National Center for Education Statistics. Washington, DC: U.S. Government Printing Office.

Rehabilitation Act Section 504, 29 U.S.C. § 794 (1973).

Rehabilitation Act Section 508, 29 U.S.C. § 794d (1973).

Scanlon, E., \& Chini, J. J. (2019). Physics instructors' views about supporting learner variation: modifying the inclusive teaching strategies inventory, 2019 PERC Proceedings. https://doi.org/10.1119/perc.2019.pr.Scanlon.

Scanlon, E., Legron-Rodriguez, T., Schreffler, J., Ibadlit, E., Vasquez, E., \& Chini, J. J. (2018a). Postsecondary chemistry curricula and universal design for learning: Planning for variations in learners' abilities, needs, and interests. Chemistry Education Research and Practice, 19(4), 1216-1239. https://doi.org/10.1039/ C8RP00095F.

Scanlon, E., Schreffler, J., James, W., Vasquez, E., \& Chini, J. J. (2018b). Postsecondary physics curricula and Universal Design for Learning: Planning for diverse learners. Physical Review Physics Education Research, 14(2), 020101. https://doi.org/10.1103/PhysRevPhysEducRes.14.020101.

Scott, G. A. (2009). Higher education and disability: Education needs a coordinated approach to improve its assistance to schools in supporting students. Government Accountability Office, 10(33), 1-51. 
Sloan, D., Gregor, P., Booth, P., \& Gibson, L. (2002). Auditing accessibility of UK Higher Education web sites. Interacting with Computers, 14(4), 313-325. https://doi.org/10.1016/50953-5438(01)00056-X.

Solovieva, T. I., \& Bock, J. M. (n.d.2014). Monitoring for accessibility and university websites: Meeting the needs of people with disabilities. Journal of Postsecondary Education and Disability, 27(2), 113-127.

Sparks, R. L., \& Lovett, B. J. (2009). College students with learning disability diagnoses: Who are they and how do they perform? Journal of Learning Disabilities, 42(6), 494-510. https://doi.org/10.1177/0022219409338746.

Straumsheim, C. (2017). New baseline for accessibility. Inside Higher Ed https:// www.insidehighered.com/news/2017/02/03/experts-say-rehabilitation-actrefresh-sets-new-baseline-accessibility-standards.

Tandy, C., \& Meacham, M. (2009). Removing the barriers for students with disabilities: accessible online and web-enhanced courses. Journal of Teaching in Social Work, 29(3), 313-328. https://doi.org/10.1080/08841230903022118.

Tashakkori, A., \& Teddlie, C. (Eds.) (2003). Handbook of mixed methods in social \& behavioral research. Thousand Oaks: Sage.

Taylor, Z. W. (2018). Web accessibility: not just for tech experts anymore. Disability Compliance for Higher Education, 23(9), 5. https://doi.org/10.1002/dhe.30416.

Teddlie, C., \& Tashakkori, A. (2006). A general typology of research designs featuring mixed methods. Research in the Schools, 13(1), 12-28.

Teddlie, C., \& Yu, F. (2007). Mixed methods sampling: a typology with examples. Journal of Mixed Methods Research, 1(1), 77-100. https://doi.org/10.1177/1 558689806292430 .

Tenon LLC. (2018). Tenon: services. Retrieved from https://tenon.io/services. php\#testing.

Tenon LLC. (2020). Tenon: understanding issue reports in Tenon.io API response. Retrieved from https://tenon.io/services.php\#testing.

Thompson, A. R., Bethea, L., \& Turner, J. (1997). Faculty knowledge of disability laws in higher education: a survey. Rehabilitation Counseling Bulletin, 40(3), 166-180.

Thompson, T., Burgstahler, S., \& Comden, D. (2003). Research on web accessibility in higher education. Information Technology and Disabilities, 9(2).

Thompson, T., Burgstahler, S., \& Moore, E. J. (2010). Web accessibility: a longitudinal study of college and university home pages in the northwestern United States. Disability and Rehabilitation. Assistive Technology, 5(2), 108-114. https://doi.org/10.3109/17483100903387424.

Timbi-Sisalima, C., Amor, C. I. M., Otón, S., Hilera, J. R., \& Aguado-Delgado, J. (2018). Comparative analysis of online web accessibility evaluation tools. In Information systems development: complexity in information systems development.

Web and Mobile Accessibility Direction (2016). Retrieved from https://www.w3. org/WAl/policies/european-union/\#web-and-mobile-accessibility-directive.

World Wide Web Consortium (2016). Understanding conformance. Retrieved from https:/www.w3.org/TR/UNDERSTANDING-WCAG20/conformance.html.

World Wide Web Consortium (2018). Using ARIA: W3C working draft. https://www. w3.org/TR/using-aria/\#NOTES

World Wide Web Consortium, (2019a). Web accessibility laws \& policies. Retrieved from https://www.w3.org/WAl/policies.

World Wide Web Consortium (2019b). Cognitive accessibility at W3C. Retrieved from https://www.w3.org/WAl/cognitive/.

World Wide Web Consortium (2019c). WAl-ARIA authoring practices 1.2. Retrieved from https://www.w3.org/TR/wai-aria-practices-1.2/.

\section{Publisher's Note}

Springer Nature remains neutral with regard to jurisdictional claims in published maps and institutional affiliations.

\section{Submit your manuscript to a SpringerOpen ${ }^{\circ}$ journal and benefit from:}

- Convenient online submission

- Rigorous peer review

- Open access: articles freely available online

High visibility within the field

- Retaining the copyright to your article

Submit your next manuscript at $\boldsymbol{\nabla}$ springeropen.com 